\title{
Evaluation of Genetic Polymorphisms of $N$-acetyltransferase 2 and Relation with Chronic Myeloid Leukemia
}

\author{
Entesar M Tebien ${ }^{1,2 *}$, Hiba B Khalil ${ }^{3}$, Jeremy Mills ${ }^{4}$, Abozer Y. Elderdery ${ }^{5,6 *}$
}

\begin{abstract}
Objectives: The N-Acetyltransferase 2 (NAT2) gene encodes a key enzyme involved in xenobiotic metabolism, which contributes to the detoxification of numerous cancer therapy-induced products. However, the NAT2 genotype/phenotype is not fully understood and few studies have reported its relationship with CML. The aim of this study was to determine whether its polymorphisms (C481T, G590A,803A>G and $857 G>A$ ) have a role in chronic myeloid leukemia susceptibility (CML) in Sudanese population. Methods: We performed a case- control study. DNA from 200 CML patients and 100 controls was analyzed for the NAT2 polymorphisms using PCR-RFLP assay. Results: The study showed NAT2 polymorphisms 803AG are associated with CML protection by a factor of 2.3, (OR $=0.044,95 \% \mathrm{CI}: 0.020-0.095, \mathrm{p}=0.000)$. The study indicated that the heterozygous $(\mathrm{GA})$ and mutant $(\mathrm{AA})$ variants of the G857A genotype also offer protection, $(\mathrm{OR}=0.002,95 \% \mathrm{CI}: 0.002-0.019, \mathrm{p}=0.000)$ and $(\mathrm{OR}=0.018,95 \%$ CI: 0.002-0.133, $\mathrm{p}=0.000)$, respectively. Conclusion: There was no significant difference in CML diagnosis among Sudanese cases with the $481 \mathrm{C} \rightarrow \mathrm{T}$ and $590 \mathrm{G} \rightarrow \mathrm{A}$ polymorphisms. But patients with the compound NAT2 genotypes 481CT/803 AG, 590AG/ 803AG, 590AG/ 803GG, 590AA/ 803AG and 590GG/ 803AG were found to have a reduced risk. The current study demonstrates that polymorphisms of NAT2 A803G and G857A might also act as protective factors against developing the disease.
\end{abstract}

Keywords: CML. NAT2- single nucleotide polymorphism

Asian Pac J Cancer Prev, 21 (12), 3711-3717

\section{Introduction}

Chronic myeloid leukemia (CML) is one of a group of diseases referred to as a myeloproliferative disorder of pluripotential hemopoietic stem cells (HSCs). Here, chromosomal translocation leads to an oncogenic $B C R-A B L$ gene fusion, which enhances tyrosine kinase (TK) activity. Anomalously activated kinases disturb downstream signaling pathways and cause abnormal proliferation, differentiation and resistance to cell death (Flis and Chojnacki, 2019). Cancer susceptibility and CML is related to inherited differences in the capability of xenobiotic enzymes to eliminate foreign agents (Kassogue et al., 2015). xenobiotic metabolizing enzymes are a primary line of defense against bioactive invaders present in tissues and organs (Rekka et al., 2019).

Xenobiotic metabolizing enzymes are classified into Phase I enzymes: (Cytochrome p450), Phase II enzymes (Glutathione-s-transferases, N-acetyltransferases), and Phase III systems, comprising multidrug resistance-associated proteins (MRPs) (Wu and Lin, 2019; Arana et al., 2016). Acetylation is a critical processes of xenobiotic metabolism and involves catalysis by acetyl CoA-dependent aryl amine $\mathrm{N}$-acetyltransferase (NAT) enzymes. This plays an essential role in protein synthesis, drugs biotransformation and DNA regulation (Santos et al., 2016).

NAT2 is located on chromosome $8(8 \mathrm{p} 21.3-23.1$ and 8p22) (Hernández-González et al., 2018) and is a Phase II drug-metabolizing enzyme. It catalyzes the detoxification of common carcinogens and the acetylation of numerous clinically used drugs eg: isoniazid, sulfonamides, procainamide, and hydrazine (Adithan and Subathra, 2016).

The NAT2 gene is highly polymorphic with more than a hundred described variant alleles (Aklillu et al., 2018), and alterations in its structure lead to a variety of responses such as susceptibility of cancer and adverse drug reactions (Dursun et al., 2018). Its polymorphisms are classified as rapid, intermediate, and slow acetylation

${ }^{1}$ Faculty of Medical Laboratory Sciences, Department oF Hematology, Al Neelain University, Sudan. ${ }^{2}$ Faculty of Applied Medical Sciences, Clinical Laboratory Sciences, Shaqra University, Saudi Arabia. ${ }^{3}$ Faculty of Medical Laboratory Sciences, Al Neelain Stem Cell Center, Al Neelain University, Sudan. ${ }^{4}$ School of Pharmacy and Biomedical Sciences, University of Portsmouth, UK. ${ }^{5}$ Faculty of Applied Medical Sciences, Clinical Laboratory Sciences, Jouf University, Saudi Arabia. ${ }^{6}$ Faculty of Medical Laboratory Sciences, Department of Hematology, University of El Imam El Mahdi, Sudan. *For Correspondence: abozer904@hotmail.com/ ayelderdery@ju.edu.sa 
phenotypes, dependent on the degree of alteration of gene and protein products (Salazar-González et al., 2018; Selinski et al., 2015).

Several studies have attempted to explain the association between NAT2 polymorphism and numerous cancer types including breast, lung cancer, acute lymphoblastic leukemia and acute myeloid leukemia (Liu et al., 2015; Zou et al., 2017; Hara et al., 2017). However, there are only a limited number of published studies on its association with CML (Ouerhani et al., 2011; Lemos et al., 1999), and this study focuses on the impact of NAT2 (C481T (rs1799929), G590A (rs1799930), A803G (rs1208) and G857A (rs1799931) polymorphisms on the disease (Santos et al., 2016).

\section{Materials and Methods}

The study comprised 200 patients with CML (Philadelphia chromosome positive), and 100 healthy control subjects. Transcript analysis was performed in the cytogenetic lab in the Radiation and Isotopes Center of Khartoum (RICK), between August 2014 and August 2017. Subject consent was obtained from donors and the protocol ratified by the research committee of the Faculty of Medical Laboratory Science at Al-Neelain University.

CML diagnosis was based on hematological features, cytogenetics and the detection of BCR-ABL.

\section{Genotyping analysis}

A sample of EDTA anticoagulated blood $(3 \mathrm{ml})$ was collected from each subject for hematological and molecular analysis. A blood cell count was first performed with an automated cell counter (Sysmex KX-21N) and the DNA then extracted by the guanidine chloride procedure. Genotyping of NAT2 was achieved by polymerase chain reaction and restriction fragment length polymorphism (PCR-RFLP) (Michael et al., 2018).

PCR amplification was undertaken with published primers (Oqal et al., 2012), and the polymorphic reaction performed using a Protothermal Biometra T Advanced Cycler - under the protocol designated by computer program; Optimase Protocol Writer ${ }^{\mathrm{TM}}$ (touch down PCR.

RFLP analysis was performed to manufacturer' instructions using endonuclease KpnI, DdeI, TaqI, and BamHI for the detection of mutations C481T, C590A, A803G and G857A, (NEW ENGLAND Bio Labs), respectively (Ben et al., 2017).

Post PCR, the fragment length for all NAT2 polymorphisms were $547 \mathrm{bp}$ and previously reported restricted enzymes under PCR-RFLP analysis is listed in Table 1.

\section{Statistical analysis}

The Normality test was used for quantitative data with non-parametric data analyzed using ANOVA and Kruskal Wallis. A Chi square test was also used within and between groups and logistic regression was utilized to calculate Odds ratios (ORs). $95 \%$ confidence intervals (CI) were calculated using SPSS 25.0 software (SPSS Inc, Chicago, IL, USA), and a p-value benchmark of $<0.05$ was considered statistically significant.

\section{Results}

The frequency of NAT2 polymorphisms according to gender among the patients was displayed in Table 2 . A total of $200 \mathrm{CML}$ patients were enrolled in this study. CML patients comprised of 132 males and 68 females. Regrading to NAT2 gene C481T polymorphism in the case group, the frequencies of the males were carrying CC, CT, and TT genotypes were $1.5 \%, 12.5 \%$, and $52 \%$, with a frequency of $0.5 \%, 6 \%$, and 27.5 in the females. Whereas the frequencies of genotypes $\mathrm{AA}, \mathrm{AG}$, and GG in NAT2 gene A803G polymorphism in the male were $36.5 \%, 9 \%$, and $20.5 \%$, and $19 \%, 6.5 \%$ and $8.5 \%$ in females, respectively. The GG, GA, and AA genotypes of NAT2 G590A polymorphism were $14 \%, 38.5 \%$, and $13.5 \%$ among the males, and $5.5 \%, 20.5 \%$, and $8 \%$ in the females. Finally, the males carrying the GG, GA, and AA genotypes of NAT2 gene G857A SNP were 23.5\%, 0.5\%, and $42 \%$, whereas, in the females, $15.5 \%, 0.5 \%$, and $18 \%$ respectively. None of the differences between genders were statistically significant at $(\mathrm{P}>0.05)$. Therefore, CML patients showed no statistical difference in NAT2 genotyping according to gender.

The distribution by age with NAT2 genotypes among case groups with CML, is shown in Table 3. The overall mean age of CML patients was $45.06 \pm 12.337 \mathrm{yrs}$. The mean age of individuals carrying $\mathrm{CC}, \mathrm{CT}$, TT genotypes of NAT2 C481T gene polymorphism were $49.5 \pm 5.6,45.41$ \pm 11.8 , and $44.86 \pm 12.7 \mathrm{yrs}$, respectively. The mean age of CML patients carrying AA, AG, and GG of $N A T 2 * 5 G$ (A803G) gene polymorphism were $46.12 \pm 11.8,43.06$ \pm 10.5 , and $44.09 \pm 14.2 \mathrm{yrs}$, respectively. In the case of NAT2 (G590A) gene polymorphism, the mean age of the individuals carrying the GG, GA, and AA genotypes

Table 1. Restriction Fragment Pattern of Various NAT2 Polymorphisms Enzyme Units BP Fragments

\begin{tabular}{|c|c|c|c|}
\hline Polymorphism & Enzyme -unite & Wild type & Mutant type \\
\hline \multirow[t]{2}{*}{$481 \mathrm{C}>\mathrm{T}$} & Kpn 1(2U) & CC: 433 and 114 bp & Heterozygous CT: 547,433 and $114 \mathrm{bp}$ \\
\hline & & & Homozygous TT: $547 \mathrm{bp}$ \\
\hline \multirow[t]{2}{*}{$857 \mathrm{G}>\mathrm{A}$} & & GG:490+57 bp & Heterozygous GA: 547,490 and $57 \mathrm{bp}$ \\
\hline & & & Homozygous AA: 547bp \\
\hline \multirow[t]{2}{*}{$590 \mathrm{G}>\mathrm{A}$} & BamH 1(4U)) & GG:222,170 and155bp & Heterozygous GA:392,222,170 and $155 \mathrm{bp}$ \\
\hline & & & Homozygous AA:392 and 155 bp \\
\hline \multirow[t]{2}{*}{$803 \mathrm{~A}>\mathrm{G}$} & Taq1(4U) & AA: 345,137 and $65 \mathrm{bP}$ & Heterozygous AG: $345,137,114$ and $65 \mathrm{bp}$ \\
\hline & & & Homozygous GG:345,114and 65 bp \\
\hline
\end{tabular}


Table 2. Frequency of NAT2 Genotyping According to Gender among Patient

\begin{tabular}{lcccc}
\hline Genotyping & & Male & Female & P-value \\
\hline NAT2*5A & CC & $3(1.5 \%)$ & $1(0.5 \%)$ & 0.9 \\
$(\mathrm{C} 481 \mathrm{~T})$ & CT & $25(12.5 \%)$ & $12(6 \%)$ & \\
& TT & $104(52 \%)$ & $55(27.5 \%)$ & \\
NAT2*5G & AA & $73(36.5 \%)$ & $38(19 \%)$ & 0.487 \\
$($ A803G) & AG & $18(9 \%)$ & $13(6.5 \%$ & \\
& GG & $41(20.5 \%)$ & $17(8.5 \%)$ & \\
NAT2*6B & GG & $28(14 \%)$ & $11(5.5 \%)$ & 0.667 \\
$($ G590A) & GA & $77(38.5 \%)$ & $41(20.5 \%)$ & \\
& AA & $27(13.5 \%)$ & $16(8 \%)$ & \\
NAT2*7B & GG & $47(23.5 \%)$ & $31(15.5 \%)$ & 0.328 \\
$($ G857A) & GA & $1(0.5)$ & $1(0.5)$ & \\
& AA & $84(42 \%)$ & $36(18 \%)$ & \\
Total & & $132(66 \%)$ & $68(34 \%)$ & \\
\hline
\end{tabular}

were $44.79 \pm 12.7,45.23 \pm 12.3$, and $44.81 \pm 12.4 \mathrm{yrs}$ respectively. Whereas, the mean ages of individuals carrying GG, GA, and AA genotypes were $45.69 \pm 11.1$, $50.00 \pm 11.3$, and $44.56 \pm 13.2$ yrs respectively. The data showed that no significant differences were observed with age regarding the presence of NAT2 C481T, A803G, G90A , and G857A genotypes.

The distribution of NAT2 C481T, A803G, G590A and G857A genotypes and alleles in CML patients and the control was also taken, with the following results:

Frequency of the NAT2481 CC genotype was slightly higher among CML patients $(2.0 \%)$ when compared to the control (1.0\%). Additionally, 481CT genotype frequency
Table 3. Age Distribution According to NAT2 Genotypes among Case Group with CML

\begin{tabular}{llcc}
\hline Genotype $(\mathrm{N})$ & & Mean \pm SD & P- value \\
\hline NAT2*5A & CC (4) & $49.5 \pm 5.6$ & 0.608 \\
$(\mathrm{C} 481 \mathrm{~T})$ & CT $(37)$ & $45.41 \pm 11.8$ & \\
& TT (159) & $44.86 \pm 12.7$ & \\
NAT2*5G & AA (111) & $46.12 \pm 11.8$ & 2.15 \\
$($ A803G) & AG (31) & $43.06 \pm 10.5$ & \\
& GG (58) & $44.09 \pm 14.2$ & \\
NAT2*6B & GG (39) & $44.79+12.7$ & 0.83 \\
$($ G590A) & GA (118) & $45.23 \pm 12.3$ & \\
& AA (43) & $44.81 \pm 12.4$ & \\
NAT2*7B & GG (78) & $45.69 \pm 11.1$ & 0.658 \\
(G857A) & GA (2) & $50.00+11.3$ & \\
& AA (120) & $44.56+13.2$ & \\
Mean age & & $45.06 \pm 12.337$ & \\
\hline
\end{tabular}

was slightly higher among CML patients (18.5\%) than the control $(15.0 \%)$, but not of statistical significance $(\mathrm{p}=0.677)$.

A similar statistical difference was found in frequency of the 481 TT genotype, which was only slightly higher in the control $(84.0 \%)$ than the patient group $(79.5 \%)$, (OR $=0.473$, 95\% CI:0.052-4.302, $\mathrm{p}=0.506)$. Moreover, little difference in $\mathrm{T}$ allele frequency was found, it being recorded in $92.5 \%$ of the control and $88.75 \%$ of CML patients, with a $\mathrm{p}=0.149$.

From NAT2 A803G samples however, frequency of 803AA was significantly higher among CML patients compared to the control, its presence being $55.5 \%$ and

Table 4. Association between NAT 2 C481T, A803G, G590A and NAT2 G857Agenotype and Risk of CML

\begin{tabular}{|c|c|c|c|c|c|c|}
\hline Polymorphisms & & Patient $\mathrm{N}=200(\%)$ & Control $\mathrm{N}=100(\%)$ & Odd ratio & $95 \% \mathrm{CI}$ & P-value \\
\hline \multirow[t]{5}{*}{ NAT2C481T } & $\mathrm{CC}$ & $4(2.0)$ & $1(1.0)$ & Ref & & \\
\hline & CT & $37(18.5)$ & $15(15)$ & 0.617 & $0.064-5.981$ & 0.677 \\
\hline & TT & $159(79.5)$ & $84(84)$ & 0.473 & $0.052-4.302$ & 0.506 \\
\hline & $\mathrm{C}$ allele & $45(11.3)$ & $15(7.5)$ & 0.639 & $0.85-2.88$ & 0.149 \\
\hline & T allele & $355(88.8)$ & $185(92.5)$ & & & \\
\hline \multirow[t]{5}{*}{ NAT2A803G } & AA & $111(55.5)$ & $10(10.0)$ & Ref & & \\
\hline & $\mathrm{AG}$ & $31(15.5)$ & $64(64.0)$ & 0.044 & $0.020-.095$ & $0.000 *$ \\
\hline & GG & $58(29.0)$ & $26(26.0)$ & 0.201 & $0.091-.445$ & $0.000^{*}$ \\
\hline & A allele & $253(63.3)$ & $84(42)$ & 0.419 & $1.68-3.66$ & $0.000 *$ \\
\hline & $\mathrm{G}$ allele & $147(36.8)$ & $116(58)$ & & & \\
\hline \multirow[t]{5}{*}{ NAT2 (G590A) } & GG & $59(29.5)$ & $23(23)$ & Ref & & \\
\hline & $\mathrm{AG}$ & $118(59)$ & $67(67)$ & 0.687 & $0.389-1.211$ & 0.194 \\
\hline & $\mathrm{AA}$ & $23(11.5)$ & $10(10)$ & 0.897 & $0.370-2.173$ & 0.809 \\
\hline & G allele & $236(59)$ & $113(56.5)$ & 0.793 & $0.64-1.27$ & 0.0 .588 \\
\hline & A allele & $164(41)$ & $87(43.5)$ & & & \\
\hline \multirow[t]{5}{*}{ NAT2 (G857A) } & GG & $79(39.5)$ & $1(1.0)$ & Ref & & \\
\hline & GA & $2(1.0)$ & $16(16.0)$ & 0.002 & $0.000-.019$ & $0.000 *$ \\
\hline & AA & $119(59.5)$ & $83(83.0)$ & 0.018 & $0.002-.133$ & $0.000^{*}$ \\
\hline & $\mathrm{G}$ allele & $160(40)$ & $16(8)$ & 0.13 & $4.43-0.13 .7$ & $0.000 *$ \\
\hline & A allele & $240(60)$ & $184(92)$ & & & \\
\hline
\end{tabular}




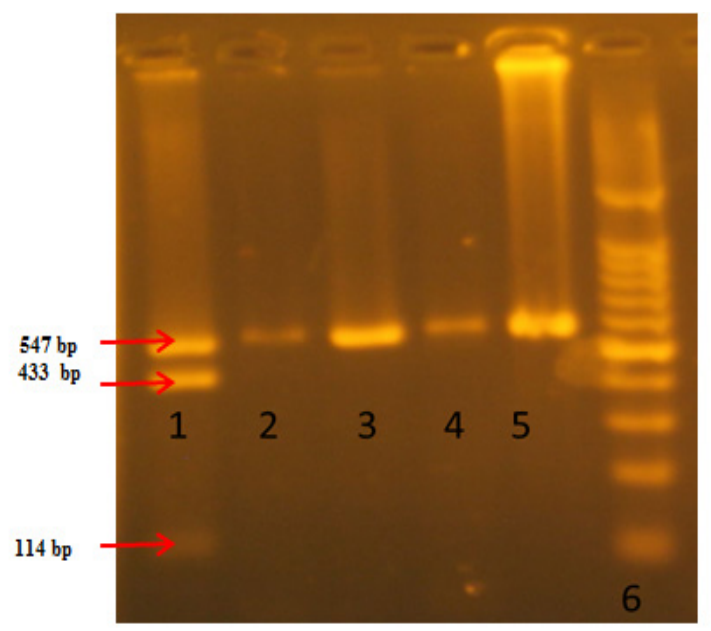

Figure 1. Detection of NAT2 Polymorphisms-C 481T on $4 \%$ Agarose Gel. DNA product digested with restriction enzyme KpnI for C481T,. Lane 1: heterozygous CT $(547,433$ and $114 \mathrm{pb}$ ), lane 2, 3,4 and 5( un cut product 547bp) homozygous mutant TT. Lane 6: : Molecular weight marker $100 \mathrm{bp}$.

$29.0 \%$, respectively $(\mathrm{OR}=0.044,95 \%$ CI:0.020-0.095, $\mathrm{p}=0.000)$.

Frequency of the homozygous mutant $803 \mathrm{GG}$ and heterozygous 803AG was higher in the control than CML patients. Incidence of the homozygous mutant $803 \mathrm{GG}$ was found in $26 \%$ of the control as opposed to $10 \%$ of CML patients, $(\mathrm{OR}=0.201,95 \% \mathrm{CI}: 0.091-0.445, \mathrm{p}=0.0 .000)$, and presence of the heterozygous $803 \mathrm{AG}$ was $64 \%$ in the control and just $15.5 \%$ of CML cases $(\mathrm{OR}=0.44,95 \%$ CI: $0.020-095, \mathrm{p}=0.000)$.

The mutant allele $\mathrm{G}$ was also significantly higher in control subjects when compared with cases at $58 \%$ and

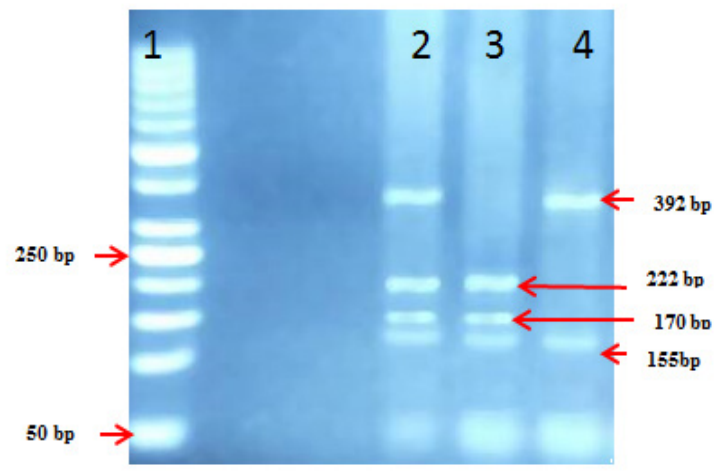

Figure 2. Detection of NAT2- Polymorphisms on $4 \%$ Agarose Gel. DNA product digested with restriction enzyme Taq1 for G590A,Lane 1:Molecularweightmarker 50 bp. Lane 2: hetrozygous GA $(392,22,170 \& 155 b p)$. Lane 3: wild type GG(222,170\&155bp). Lane 4: homozygoyous mutant AA (392\&155bp).

$36 \%$, respectively.

From NAT2 G590A samples, 590GG and 590AA genotype distribution was higher among CML patients $(29.5 \%)$ and $(11.5 \%)$ respectively, compared to control group $(23.0 \%)$ and $(10.0 \%)$. With OR $=0.897,95 \% \mathrm{CI}$ : $0.370-2.137$ and $p=0.809$ however, this difference was not considered significant.

NAT2 590AG was higher in the healthy control (67\%) than CML patients $(59 \%)$, but again, with OR $=0.687$, 95\% CI:0.389-1.211 and $\mathrm{p}=0.194$, this difference was not significant. Accordingly, presence of the $\mathrm{G}$ allele was higher in CML patients (59.0\%) compared to the control $(56.5 \%)$, but again of no significant difference $(\mathrm{p}=0$. $558)$. NAT2 $857 \mathrm{GG}$ was also higher in patients $(39.5 \%)$ compared to the control $(1.0 \%)$.

Table 5. NAT2 Genotype Interaction Analysis in CML Patient and Control

\begin{tabular}{|c|c|c|c|c|c|c|}
\hline \multicolumn{2}{|c|}{ NAT2C481T and NAT2GA803G } & \multicolumn{2}{|c|}{ Case } & \multirow[t]{2}{*}{ Odd ratio } & \multirow[t]{2}{*}{$95 \% \mathrm{CI}$} & \multirow[t]{2}{*}{ P-value } \\
\hline & & Control N (\%) & Patient N (\%) & & & \\
\hline \multirow[t]{8}{*}{ Comb1 } & $\mathrm{CC} / \mathrm{AA}$ & $1(1 \%)$ & $4(2 \%)$ & Ref & & \\
\hline & $\mathrm{CC} / \mathrm{GG}$ & $1(1 \%)$ & $1(0.5 \%)$ & 0.25 & $(0.01-8.56)$ & 0.442 \\
\hline & $\mathrm{CT} / \mathrm{AA}$ & $3(3 \%)$ & $22(11 \%)$ & 1.83 & $(0.15-22.36)$ & 0.635 \\
\hline & $\mathrm{CT} / \mathrm{AG}$ & $11(11 \%)$ & $1(0.5 \%)$ & 0.023 & $(0.001-.456)$ & $0.013 *$ \\
\hline & $\mathrm{CT} / \mathrm{GG}$ & $1(1 \%)$ & $15(7.5 \%)$ & 3.75 & $(0.190-74.06)$ & 0.385 \\
\hline & TT / AA & $7(7 \%)$ & $84(42 \%)$ & 3 & $(0.294-30.62)$ & 0.354 \\
\hline & $\mathrm{TT} / \mathrm{AG}$ & $52(52 \%)$ & $31(15.5 \%)$ & 0.15 & $(0.016-1.39)$ & 0.095 \\
\hline & $\mathrm{TT} / \mathrm{GG}$ & $24(24 \%)$ & $42(21 \%)$ & 0.44 & $(0.046-4.14)$ & 0.471 \\
\hline \multicolumn{2}{|c|}{ NAT2G590A and NAT2A803G } & Control N (\%) & Patient N (\%) & Odd ratio & $95 \% \mathrm{CI}$ & P-value \\
\hline \multirow[t]{9}{*}{ Comb2 } & $\mathrm{GG} / \mathrm{AA}$ & $3(3 \%)$ & $32(16 \%)$ & Ref & & \\
\hline & $\mathrm{GG} / \mathrm{AG}$ & $17(17 \%)$ & $1(0.5 \%)$ & 0.01 & $(0.001-0.057)$ & $0.000^{*}$ \\
\hline & $\mathrm{GG} / \mathrm{GG}$ & $3(3 \%)$ & $27(13.5 \%)$ & 0.84 & $(0.157-4.53)$ & 0.843 \\
\hline & $\mathrm{AG} / \mathrm{AA}$ & $7(7 \%)$ & $59(29.5 \%)$ & 0.79 & $(0.191-3.27)$ & 0.745 \\
\hline & $\mathrm{AG} / \mathrm{AG}$ & $38(38 \%)$ & $31(15.5 \%)$ & 0.08 & $(0.021-0.27)$ & $0.000^{*}$ \\
\hline & $\mathrm{AG} / \mathrm{GG}$ & $21(21 \%)$ & $27(13.5 \%)$ & 0.12 & $(0.032-.45)$ & $0.002 *$ \\
\hline & $\mathrm{AA} / \mathrm{AA}$ & $1(1 \%)$ & $19(9.5 \%)$ & 1.7 & $(0.173-18.37)$ & 0.628 \\
\hline & $\mathrm{AA} / \mathrm{AG}$ & $10(10 \%)$ & $4(2 \%)$ & 0.04 & $(0.007-0.19)$ & $0.000 *$ \\
\hline & GG/ AA & $3(3 \%)$ & $32(16 \%)$ & 0.141 & $(0.001-0.06)$ & $0.073 *$ \\
\hline
\end{tabular}

Key: $(*)$, denote; $*$, significant $\mathrm{p}$. value 
Frequency of 857GA and 857AA in the NAT2G857A genotype was higher in the control at $16.0 \%$ and $83.0 \%$ respectively, as opposed to $1.0 \%$ and $59.5 \%$ of CML patients. This difference was highly significant, $(\mathrm{OR}=0.002,95 \% \mathrm{CI}: 0.000-0.19, \mathrm{p}=0.0 .000)$ and $(\mathrm{OR}$ $=0.018,95 \%$ CI:0.002- $0.133, \mathrm{p}=0.0 .000)$ respectively.

Mutant allele A presence was significantly higher in the control, it being found in $92 \%$ of healthy participants as opposed to $60 \%$ of CML cases, $(p=0$. 0.000 ). Furthermore, logistical analysis of carriers of the homozygous mutant heterozygous to 1208 and rs 1799931, were both associated with CML protection - unlike those with the homozygous wild type allele, $(\mathrm{OR}=0.89,95 \%$ CI: $0.044-0.181, p=0.000)$ and $(\mathrm{OR}=0.015,95 \% \mathrm{CI}$ : $0.002-0.0113, \mathrm{p}=0.000)$, respectively, Please see results in Table 4.

Frequency of NAT2 genotype combinations among patients and the control is found in Table 5. Within the NAT2C481T and NAT2GA803G combination, CTAGwas the only genotype represented significantly more in patients $(11 \%)$ compared to control $(0.5 \%)$ with $(\mathrm{OR}=$ $.023,95 \% \mathrm{CI}:(.001-.456, \mathrm{p}=.013)$. CTAG is therefore associated with protection from CML.

Additionally, five polymorphisms were considered highly significant in decreasing CML risk and these had a synergistic effect on each other. They were represented in the following combinations:

NAT2481CT/NAT2 803AG $(\mathrm{OR}=0.023,95 \% \mathrm{CI}$ : $0.001-0.456, \mathrm{p}=0.013)$

NAT2 590GG/ NAT2803AG $(\mathrm{OR}=0.006,95 \% \mathrm{CI}$ : $0.001-.057, \mathrm{p}=0.000)$

NAT2 590AG/ NAT2 803AG $(\mathrm{OR}=0.076,95 \% \mathrm{CI}$ : $0.21-0.274, \mathrm{p}=0.000)$

NAT2590AG/ NAT2803GG $(\mathrm{OR}=0.121,95 \% \mathrm{CI}$ : $0.032-0.448, \mathrm{p}=0.000)$

NAT2 590AA/ NAT2803AG $(\mathrm{OR}=0.038,95 \% \mathrm{CI}$ : $0.007-0.197, \mathrm{p}=0.000)$

NAT2 590GG/ NAT2803AA $(\mathrm{OR}=0.006,95 \% \mathrm{CI}$ : $0.001-0.057, \mathrm{p}=0.000)$.

\section{Discussion}

The NAT2 acetylated genotype has a large influence on cancer predisposition (Jiang et al., 2019) and may induce susceptibility to tumors arising from industrial and environmental aryl amines (Mitchell, 2019). To date, a limited number of studies have been published in Sudan concerning inter-individual and inter-ethnic differences in NAT2 allele frequencies, (Ali et al., 2019; Al-Yahyaee et al., 2007) but this is the first investigation into its genetic variations $(481 \mathrm{C} \rightarrow \mathrm{T}, 590 \mathrm{G} \rightarrow \mathrm{A}, 803 \mathrm{~A} \rightarrow \mathrm{G}$ and $857 \mathrm{G} \rightarrow \mathrm{A}$ ) and their association with CML susceptibility and progression (Kotila et al., 2019).

Our results revealed no statistical difference in the presence of the heterozygous 481CT and mutant 590AA genotypes between CML patients and the control. In patients, 481CT genotype presence was actually slightly higher in patients $(18.5 \%)$ than the control $(15.0 \%)$, (OR $=0.617,95 \%$ CI: 0.064-5.981, $\mathrm{p}=0.677)$. Conversely, a slightly higher 481 TT genotype frequency was found in the control $(84.0 \%)$, as opposed to $(79.5 \%)$ of patients group. Again however, this was not significant difference $(\mathrm{OR}=0.473,95 \% \mathrm{CI}: 0.052-4.302, \mathrm{p}=0.506)$.

Moreover, NAT2 590GA and AA presence was of no significant difference between diagnosed CML patients and the control $(\mathrm{OR}=0.687,95 \% \mathrm{CI}$ : 0.389-2.1.211, $\mathrm{p}=0.194)$ and $(\mathrm{OR}=0.897,95 \% \mathrm{CI}: 0.370-2.173, \mathrm{P}=0$. 809). These results are partially in agreement with Silveira and coworkers regarding NAT2 variant polymorphism presence, in ALL patients and their control (Silveira et al., 2012). The current study is also partially consistent with an earlier study conducted by Lemos and co-workers, who failed to find an association between these polymorphisms and other types of hematological malignancy(Lemos et al., 1999). Research by Ouerhani et al., (2011) investigated the association between xenobiotic metabolizing gene polymorphisms and susceptibility to $A M L, C M L, C L L$, and $A L L$ in the Tunisian population, and found that NAT2 polymorphisms do not influence either predisposition or prognosis in CML patients.

More specifically, studies amongst Han Chinese populations found no significant association between rs1799930 and AML susceptibility which partially concords with Dursun et al, who revealed that rs1799929, rs1799930, and rs1799931 polymorphisms of the NAT-2 gene are not risk factors for the development of psoriasis (Dursun et al., 2018; Zou et al., 2017).

In contrast with our findings, another study has demonstrated that AML risk increases in patients with rapid or intermediate NAT2 genotypes (Ouerhani et al., 2011), and Gra et al showed that NAT2 genotypes 341T/T, $481 \mathrm{C} / \mathrm{C}, 590 \mathrm{G} / \mathrm{G}$ are more frequent in children with acute leukemia than in the population control (Gra et al., 2008).

The association of NAT2 polymorphisms with the predisposition of acute leukemia has produced controversial results (Zhu et al., 2019). Gra et al., (2008) found ALL and AML patients expressed a rapid acetylation phenotype, suggesting that the increased frequency of malignancy (acute leukemia) was due to enhanced activation of aryl amines as potential pro-carcinogens. It is already been shown that the rapid acetylation phenotype occurs more frequently in patients with colon and colorectal cancer (Kabir and Rehman, 2018).

Gong et al., (2001) in addition to a meta-analysis of prostate cancer, disagree with studies undertaken on solid tumors in adults which demonstrate that NAT2 slow acetylator individuals are at a greater risk of prostate and lung cancer (Koda et al., 2017; Liu et al., 2015).

Our data demonstrates the protective effect of NAT2A 803G and G857A against CML. 803AG in its heterozygous form offers approximately 2.3 fold protection and the heterozygous (GA) and mutant (AA) in the $857 \mathrm{G} \rightarrow \mathrm{A}$ genotype, both decreased risk also. Our study is in harmony with Zou et al., (2017) who revealed that the $r s 1799931 G>A N A T 2$ gene replaced glycine by glutamic acid in the 286th amino acid of the protein. The locus mutation alters enzyme activity and the further effects of drug metabolism in the activation of carcinogens, in raising or lowering cancer incidence.

A major meta-analysis has reported rs1799931 as a protective factor against cancer progression (Tian et al., 2014). However, Kamel et al., (2015) reported that

Asian Pacific Journal of Cancer Prevention, Vol $213 \mathbf{3 7 1 5}$ 
NAT2 $* 5 \mathrm{~B}(314 \mathrm{~T}>\mathrm{C}, 481 \mathrm{C}>\mathrm{T}$ and $803 \mathrm{~A}>\mathrm{G}) \& * 5 \mathrm{C}$ $(314 \mathrm{~T}>\mathrm{C}, 803 \mathrm{~A}>\mathrm{G})$ were associated with a decreased risk of ALL development, giving 1.8 and 2.4-fold protection, respectively.

This study agrees with our finding that the $803 \mathrm{~A}>\mathrm{G}$ polymorphism is associated with CML protection, to some extent. Furthermore, we found that risk also decreased as a result of the $G 590 \mathrm{~A}$ gene polymorphism, in its significant relationship with $\mathrm{A} 803 \mathrm{G}$ and $\mathrm{C} 481 \mathrm{~T}$ - when in interaction with A803G. CML patients with compound NAT2 590GG/ NAT2803AG, NAT2 590AG/NAT2803AG, NAT2 590AG/ $N A T 2803 G G, N A T 2$ 590AA/ NAT2803AG and NAT2 $590 G G / N A T 2803 A A$ genotypes were found to have a decreased risk.

The present results reveal these combinations as having a protective effect against CML development. However, Gra et al., (2008) found that the combination of GST and NAT2 genotypes greatly increased the risk of acute leukemia in childhood. This risk frequency was higher than those with the GSTT1 null genotype, GSTM1 null genotype, or NAT2 genotypes; 341T/T, 481C/C and $590 \mathrm{G} / \mathrm{G}$.

A previous study undertaken by Zheng et al., (2017) also documented the significant risk of ALL with carriers of rs1799931 and rs1801280, and that carriers of the rs1799931-GA/AA and rs1801280-TC/CC genotypes had the highest risk of all.

Our study has several limitations specifically that more SNPs within the NAT2 gene should have been studied and sample size should have been larger. In addition, the CML phases should receive greater focus.

In conclusion, there is evidence that both NAT2A $803 \mathrm{G}$ and G857A polymorphisms were associated with protection from CML in the Sudanese population. Also, the gene-gene interaction between $N A T 2$ 590GG/ NAT2803AG, NAT2 590AG/NAT2803AG, NAT2 590AG/ NAT2803GG, NAT2 590AA/ NAT2803AG and NAT2 $590 G G / N A T 2803 A A$ genotypes were associated with a decreased CML risk. However, there was no such association between C481T and G590A and CML.

\section{Acknowledgements}

The authors thank staff of the Hematology Department at the RICK in Khartoum-Sudan for their assistance with this study. Thanks also to the staff at the Research and Laboratory Unit of Al Neelain University, Sudan and University of Portsmouth, UK for their help.

\section{Ethics approval and consent to participate}

This study was approved by the research committee at the Faculty of Medical Laboratory Sciences at Al-Neelain University. The patients and health individuals provided verbal informed consent and volunteered to participate in the study. The form of consent ethics was approved the above committee.

\section{Consent for publication \\ Not applicable.}

The authors declare that they have no competing interests.

Availability of data and Materials

The data that support the findings of this study are available from the corresponding author, $[\mathrm{AE}]$, upon reasonable request.

\section{References}

Adithan C, Subathra A (2016). NAT2 gene polymorphism: covert drug interaction causing phenytoin toxicity. Indian $\mathrm{J} \mathrm{Med}$ Res, 143, 542-4.

Aklillu E, Carrillo J A, Makonne E, Bertilsson L, et al (2018). N-Acetyltransferase-2 (NAT2) phenotype is influenced by genotype-environment interaction in Ethiopians. Eur J Clin Pharmacol, 74, 903-11.

Al-yahyaee S, Gaffar U, Al-ameri MM, et al (2007). $\mathrm{N}$-acetyltransferase polymorphism among northern Sudanese. Hum Biol, 79, 445.

Ali MH, Alrasheedy AA, Kibuule D, et al (2019). Isoniazid acetylation phenotypes in the Sudanese population; findings and implications. J Clin Tuberc Other Mycobact Dis, 17, 100120 .

Arana MR, Tocchetti GN, Rigalli JP, et al (2016). Hepatic and Intestinal Multidrug Resistance Associated Protein 2: Transcriptional and Post-transcriptional Regulation by Xenobiotics. Toxicology-New Aspects to This Scientific Conundrum, pp 25-44.

Ben FN, Gam R, Kerkni E, et al (2017). Risk factors of isoniazidinduced hepatotoxicity in Tunisian tuberculosis patients. Pharmacogenomics J, 17, 372.

Dursun R, Dursun HG, Zamani AG, et al (2018). NAT2 Gene polymorphisms in Turkish patients with psoriasis vulgaris. Biomed Res Int, 2018.

Flis S, Chojnacki T (2019). Chronic myelogenous leukemia, a still unsolved problem: pitfalls and new therapeutic possibilities. Drug Des Devel Ther, 13, 825.

Gong C, Hu X, Gao Y, et al (2011). A meta-analysis of the NAT1 and NAT2 polymorphisms and prostate cancer: a huge review. Med Oncol, 28, 365-76.

Gra OA, Glotov AS, Kozhekbayeva ZM, et al (2008). Genetic polymorphism of GST, NAT2, and MTRR and susceptibility to childhood acute leukemia. J Mol Bio, 42, 187.

Hara A, Taira N, Mizoo T, et al (2017). N-acetyltransferase 2 polymorphism and breast cancer risk with smoking: a case control study in Japanese women. Breast cancer (Tokyo, Japan), 24, 254.

Hernández-González O, Ortiz-Zamudio JJ, Rodríguez-Pinal $\mathrm{CJ}$, et al (2018). Genetic polymorphisms of arylamine $\mathrm{N}$-acetyltransferases 1 and 2 and the likelihood of developing pediatric acute lymphoblastic leukemia. Leuk Lymphoma, 59, 1968-75.

Jiang WH, Wang XT, Zheng LD, et al (2019). Relationship between NAT2 polymorphisms and onset risk of acute leukemia: a systematic review and meta-analysis. Eur Rev Med Pharmacol Sci, 23, 9259-66.

Kabir S, Rehman A (2018). Carcinogenic potential of arylamine $\mathrm{N}$-acetyltransferase in Asian populations. JCRP, 5, 131-5.

Kamel AM, Ebid GTA, Moussa HS (2015). N-Acetyltransferase 2 (NAT2) polymorphism as a risk modifier of susceptibility to pediatric acute lymphoblastic leukemia. Tumour Biol, 36, 6341-8.

Kassogue Y, Dehbi H, Quachouh M, et al (2015). Association of glutathione S-transferase (GSTM1 and GSTT1) genes with chronic myeloid leukemia. Springer plus, 4, 1-5.

Jiang WH, Wang XT, Zheng LD, et al (2019). Relationship 
between NAT2 polymorphisms and onset risk of acute leukemia: a systematic review and meta-analysis. Eur Rev Med Pharmacol Sci, 23, 9259-66.

Kabir S, Rehman A (2018). Carcinogenic potential of arylamine $\mathrm{N}$-acetyltransferase in Asian populations. JCRP, 5, 131-5.

Kamel AM, Ebid GTA, Moussa HS (2015). N-Acetyltransferase 2 (NAT2) polymorphism as a risk modifier of susceptibility to pediatric acute lymphoblastic leukemia. Tumour Biol, 36, 6341-8

Kassogue Y, Dehbi H, Quachouh M, et al (2015). Association of glutathione S-transferase (GSTM1 and GSTT1) genes with chronic myeloid leukemia. Springer plus, 4, 1-5.

Koda M, Iwasaki M, Yamano Y, et al (2017). Association between NAT2, CYP1A1, and CYP1A2 genotypes, heterocyclic aromatic amines, and prostate cancer risk: a case control study in Japan. Environ Health Prev Med, 22, 72.

Kotila OA, Fawole OI, Olopade OI, et al (2019). $\mathrm{N}$-acetyltransferase 2 enzyme genotype-phenotype discordances in both HIV-negative and HIV-positive Nigerians. Pharmacogenet Genomics, 29, 106.

Lemos MC, Cabrita FJ, Silva HA, et al (1999). Genetic polymorphism of CYP2D6, GSTM1 and NAT2 and susceptibility to haematological neoplasias. Carcinogenesis, 20, 1225.

Liu C, Cui W, Cong L, et al (2015). Association between NAT2 polymorphisms and lung cancer susceptibility. Medicine, 94, e1947.

Michael G, Thier R, Blaszkewicz M, et al (2018). Algorithm for the Automated Evaluation of NAT2 Genotypes. Methods Mol Biol, 1655, 77.

Mitchell SC (2019). N-acetyltransferase: the practical consequences of polymorphic activity in man. Xenobiotica, 2019, $1-15$.

Oqal MK, Mustafa KN, Irshaid, Y M(2012). N-acetyltransferase-2 genotypes among patients with rheumatoid arthritis attending Jordan University Hospital. Genet Test Mol Biomarkers, 16, 1007-10.

Ouerhani S, Nefzi MA, Menif S, et al (2011). Influence of genetic polymorphisms of xenobiotic metabolizing enzymes on the risk of developing leukemia in a Tunisian population. Bull Cancer, 98, 95-106.

Rekka EA, Kourounakis PN, Pantelidou M (2019). Xenobiotic Metabolizing Enzymes: Impact on Pathologic Conditions, Drug Interactions and Drug Design. Curr Top Med Chem, 19, 276-91.

Salazar-González RA, Turiján-Espinoza E, Hein DW, et al (2018). Expression and genotype-dependent catalytic activity of N-acetyltransferase 2 (NAT2) in human peripheral blood mononuclear cells and its modulation by Sirtuin 1 . Biochem Pharmacol, 156, 340-7.

Santos E C, Pinto AC, Klumb E M, et al (2016). Polymorphisms in NAT2 (N-acetyltransferase 2) gene in patients with systemic lupus erythematosus. Rev Bras Reumatol, 56, 521.

Selinski S, Getzmann S, Gajewski PD, et al (2015). The ultraslow NAT2*6A haplotype is associated with reduced higher cognitive functions in an elderly study group. Arch Toxicol, 89, 2291-303.

Silveira VS, Canalle R, Scrideli CA, et al (2012). CYP3A5 and NAT2 gene polymorphisms: role in childhood acute lymphoblastic leukemia risk and treatment outcome. Mol Cell Biochem, 364, 217-23.

Tian FS, Shen L, Ren YW, et al (2014). N-acetyltransferase 2 gene polymorphisms are associated with susceptibility to cancer: a meta-analysis. Asian Pac J Cancer Prev, 15, 5621-6.

Wu KC, Lin CJ (2019). The regulation of drug metabolizing enzymes and membrane transporters by inflammation:
Evidences in inflammatory diseases and age related disorders. J Food Drug Anal, 27, 48-59.

Zheng Z, Qiao Z, Gong R, et al (2017). Association between single nucleotide polymorphism of $\mathrm{N}$-acetyltransferase 2 and susceptibility to acute lymphoblastic leukemia in Chinese Han children. Int J Clin Exp Pathol, 10, 7052-8.

Zhu X, Liu Y, Chen G, et al (2019). Association between NAT2 polymorphisms and acute leukemia risk: A meta-analysis. Medicine, 98, e14942.

Zou Y, Dong S, Xu S, et al (2017). Genetic polymorphisms of NAT2 and risk of acute myeloid leukemia: A case-control study. Medicine, 96, e7499.

This work is licensed under a Creative Commons AttributionNon Commercial 4.0 International License. 